\title{
El Obsceno Pájaro de la Noche: La Dialéctica del Chacal y el "Imbunche"
}

Aunque El obsceno pájaro de la nocbe ya ha sido tratado varias veces por los críticos (sobre todo en el número de Review del otoño,11973, que fue dedicado a Donoso), es una novela tan compleja, tan revolucionaria, que siempre cabe una interpretación más. Aquí vamos a sugerir dos interpretaciones, una estructuralista, otra jungiana, porque la novela se niega a ser contenida en una sola.

Primero hay que caracterizar la novela como obra a la vez cosmológica y hegeliana donde se desarrollan por lo menos dos dialécticas dentro de una sola persona. La dialéctica que vamos a examinar primero es la dialéctica entre la conciencia y la subconciencia, cada una encarnada en personaje distinto. La tragedia de Jerónimo, el "protagonista", es que él niega la existencia de su lado oscuro y que este "otro" se venga matándole. Los personajes fracturados expresan el temor de Donoso de que no hay unidad en la personalidad humana. Como él dijo en una entrevista con Emir Rodriguez Monegal: "I believe that I don't believe that a psychological unity exists in the human being." 1

El otro gran miedo de Donoso, íntimamente relacionado con éste, "el terror de no existir', se expresa en la novela por la segunda dialéctica, la de la creación y de la destrucción. Y a ésta la llamaremos la dialéctica del chacal y del "imbunche". E1 "imbunche", como lo pinta Donoso, es la víctima ' 'biodegradable"' capturada por las brujas y ofrecida a las fuerzas creadoras de la vida, los comedoras de carroña, que garantizan que nada se echará a perder, que la vida seguirá su lucha eterna con la entropía. Si hay protagonista - en el sentido de vencedor - en esta novela, es la naturaleza misma que crea y destruye con una falta absoluta de sentimentalidad.

El título, sin embargo, no se refiere a la naturaleza utilizando su propio punto de vista, ya que para ella nada es obsceno. El título tiene sentido sólo si nos identificamos con el personaje principal, andrógino, más o menos humano, que encarna en su cuerpo de camaleón a las dos dialécticas. Es para este personaje, Mudito-Jerónimo, o para cualquiera de nosotros que sea capaz de vida espiritual, para quien la naturaleza "is an unsubdued

1 Emir Rodríguez Monegal, “Entrevista con José Donoso", Review (otoño, 1973), p. 36. 


\section{REVISTA IBEROAMERICANA}

forest where the wolf howls and the obscene bird of night chatters". ${ }^{2}$ Vemos el desenlace de la novela llevarse a cabo dentro de una pesadilla donde las criaturas de carne se debaten brevemente por su identidad sólo para acabar sumergidas otra vez en el barro negro y sangriento de la muerte y la recreación.

Como cualquier pesadilla, la novela ignora el tiempo en orden cronológico. Además no se mueve en sentido inverso como ocurre, por ejemplo, en La muerte de Artemio Cruz de Carlos Fuentes. Quizá el propio Donoso caracteriza su técnica organizadora del tiempo novelístico cuando dice:

Las viejas como la Peta Ponce tienen el poder de plegar y confundir el tiempo, lo multiplican y lo dividen, los acontecimientos se refractan en sus manos verrugosas como en el prisma más brillante, cortan el suceder consecutivo en trozos que disponen en forma paralela, curvan esos trozos y los enroscan organizando estructuras que les sirven para que se cumplan sus designios. ${ }^{3}$

Sin embargo, dentro de este mundo atemporal de monstruos, brujos, brujas y enfermos mentales donde la vida se desarrolla según unos principios que nunca llegamos a entender, existe una suerte de realidad "burguesa" que se puede comparar a la técnica de la pintura surrealista. A pesar del ambiente de pesadilla, la mayoría de los detalles son exactos. Los personajes son de tres dimensiones; sobresalen con sus historias pasadas y sus esperanzas para el futuro. Cada sección del lienzo parece familiar; es nada más la yuxtaposición la que es única y parece fuera de nuestro mundo. O hablando todavía en términos del arte plástico, podemos referirnos a la escuela del cubismo y decir que la figura de Mudito está cortada espacial y temporalmente de tal manera que se parece al "Desnudo Bajando la Escalera" de Duchamp. El personaje está reflejado en un espejo grotesco mientras baja hacia su muerte, y lo vemos casi simultáneamente en las 543 páginas-peldaños, hasta que se esfuma en la nada.

Hay otras comparaciones tentadoras que pueden ayudar a entender la novela. Una es la de un universo que oscila entre las fuerzas de la expansión (creación) y la contracción (destrucción). Esta dialéctica, por lo menos, es el motor principal que hace funcionar a Mudito, personaje subconsciente, cuyos sentimientos alternan entre el miedo de llegar a ser "imbunche" y su deseo de paz y descanso.

Cuando Mudito no puede aguantar más y anhela la muerte, primero tiene que matar a Don Jerónimo, su parte pública, su '"persona', o él también será condenado a seguir sufriendo el martirio de la vida. Mudito se da cuenta de todo eso después de refugiarse en un asilo de viejas para escapar los sufrimientos implícitos en su relación con Jerónimo. Lo que pasa es que Mudito no toma en cuenta el hecho de que Inés, la esposa de Jerónimo, también va a refugiarse en el asilo y que él volverá a desearla. Pero Inés, personaje igualmente mágico, se convierte en su propia nana, la bruja Peta Ponce, por el mismo motivo de sentirse libre de Jerónimo.

De tal manera las dos figuras principales, masculina y femenina, son figuras de dos cabezas, dos polos opuestos. En una de sus personalidades la figura masculina encarna

2 Epigrafe a la novela que cita una carta del padre Henry James a sus hijos Henry y William.

3 José Donoso, El obsceno pájaro de la noche (Editorial Seix Barral, 1971), p. 223. Citamos por esta segunda edición 
belleza, poder y frialdad. En la otra, la subterránea, existe envidia, deformación fisica y masoquismo. En cuanto a la figura femenina que comentaremos en detalle más adelante, ella encarna en su manifestación de doncella las cualidades de belleza física y frialdad. En su papel de vieja se destaca por su lubricidad, sabiduria y aspecto físico asqueroso. Así es que cuatro personajes equivalen solamente a dos, y no debe extrañarnos que los cuatro son necesarios para engendrar al niño monstruoso, Boy.

Sin embargo, a medida que avanza la novela, las cabezas que parecian opuestas se juntan hasta llegar por fin a la identidad a través de la muerte. La transformación a la cual Donoso da más importancia es la que ocurre dentro del personaje masculino. Cuando lo vemos por primera vez, Jerónimo es elegante, soberbio, seguro de sí mismo. Su polo opuesto, Mudito-Humberto, es una persona sin cara, sin sexo, un "non person" que tiene nada más una habilidad increíble para la adaptación. La envidia de Mudito llega a ser un factor necesario para el poder sexual de Jerónimo. De esta manera los dos son necesarios para engendrar a Boy, su hijo. Y es a través del hijo monstruoso que este hombre, en sus dos aspectos, por fin realiza su destino. El Adonis es cambiado en monstruo por todos los monstruos que él ha recogido en su mundo grotesco:

...huyo tratando de arrancar con mis uñas esa máscara que no me puedo sacar aunque sé que es máscara porque esta noche es el baile de Emperatriz y yo me he disfrazado de monstruo, me rasguño la cara que sangra y sangrando me prueba que no es careta...sí me reconocí monstruo retorcido en el reflejo del estanque... ${ }^{4}$

En esta transformación del político, Jerónimo, en otro monstruo tal como aquellos que él mismo ha creado, también se puede encontrar un tema de significado social. Pero aquí nos limitamos a comentar su muerte en términos más bien psicológicos y existenciales. Jerónimo se muere (después de volverse loco) en un magnífico estanque (símbolo de la vida) porque su lado subconsciente desea la muerte, porque su esquizofrenia es demasiado dolorosa. Pero de alguna manera este lado subconsciente, el ubicuo Mudito, sigue viviendo, - - lo que sugiere quizás que el lado subconsciente del hombre es más duradero que el "ego". Para efectuar su muerte en una manera que Unamuno habria llamado un "desnacer", Mudito tiene que transformarse en el hijo milagroso e imaginario de una huérfana del asilo. Para mejor claridad llamaremos a este niño Boy II (aunque el autor le llama sólo "Boy", apellido que equivale en la novela a "niño").

El diagrama que sigue quizás ayudará a explicar la dialéctica de la fusión de los dos polos en el personaje principal.

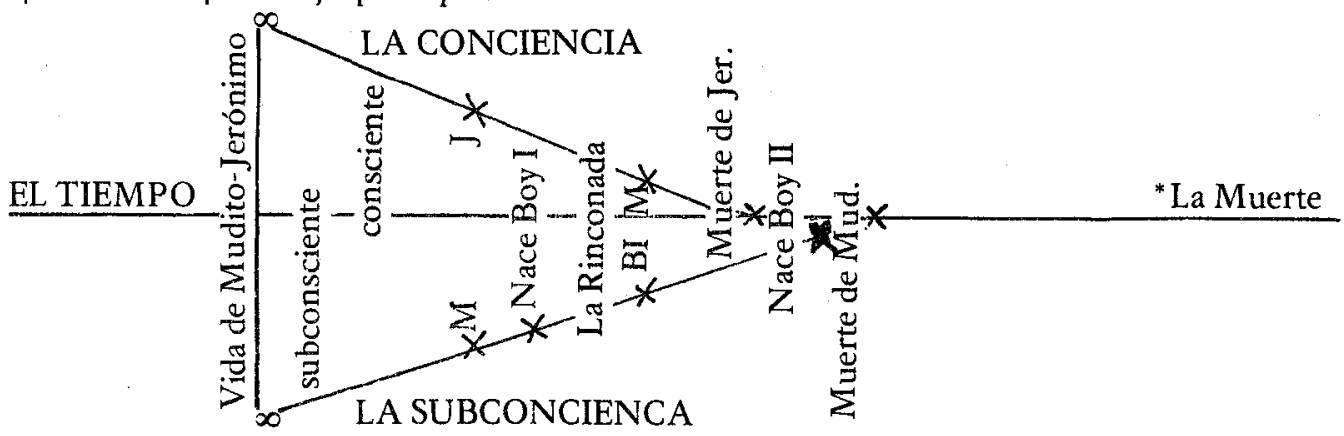

4 Op. cit., p. 504 
Podemos decir que en el eje vertical de la vida, Jerónimo es a Mudito como Mudito es a Boy. I (poder y belleza rigiendo sobre impotencia y monstruosidad). Pero cuando llevamos esta proporción al eje horizontal de la muerte, la diferencia entre las dos entidades disminuye a tal grado que desaparece por completo, y Boy I (monstruo vivo y activo) llega a ser igual a Boy II, que es sólo el fruto de la imaginación de Mudito. Es decir que todos estos personajes, que son representaciones de la misma persona, se aniquilan y funden sólo en la muerte. Vemos que en esta novela la tragedia de la persona esquizofrénica consiste en que llega a realizarse como persona entera solamente cuando ya no le queda vida. El símbolo de su totalidad, el círculo, es también la figura cero, el signo de la nada.

Siguiendo con el diagrama, vemos que Jerónimo es la parte iluminada, visible, de su ser pero que necesita sus raíces para reproducir, para realizar su potencia. Con la confusión acerca de la paternidad de Boy, empezamos a darnos cuenta que los dos polos de su carácter están fundiéndose. Después del nacimiento de Boy y su encarcelación en el mundo de los monstruos, este acercamiento ha progresado a tal grado que Mudito ahora disfruta de la misma relación con Boy que antes existía entre él y Jerónimo. Mudito llega a ser la encarnación del padre que rige el mundo monstruoso; es el único personaje con libertad de movimiento entre todos los mundos de la novela. Pero ahora Boy I, al crecer, también consigue cruzar la frontera de su mundo artificial. Y después de conocer la fruta amarga de la vida verdadera, él, como Mudito, desea regresar a la vida vegetal. El dice al Dr. Azula (que es a la vez cirujano y brujo): “...saque cuanto quiera de mi cerebro, déjeme convertido en un vegetal." 5 Un desarrollo parecido también ocurre con Boy II (la última manifestación de Mudito que utiliza el niño imaginario de la huérfana para consumar su escapatoria de la vida). A la vez victimizado y adorado por las brujas del asilo, él cuenta:

me metieron dentro de un saco, dejándome sólo la cabeza afuera,...me cosieron bien cosidito adentro para que no se vaya a mover el hiño...no me ven porque no importo, no existo, soy sólo materia pasiva sobre la que van proyectando imágenes, el niño, Boy... ${ }^{6}$

Asi es que cuando abren el saco, el "imbunche"' (Boy II) ha desaparecido por completo. E igualmente se sospecha que el deseo de Boy I de transformarse en vegetal también se ha realizado cuando en una de las últimas escenas de la novela vemos una inundación de calabazas enormes que llegan misteriosamente al asilo. De tal manera a través de una proliferación cancerosa de la vida vegetal de un lado y la reducción a la nada del otro, la figura de Jerónimo-Mudito-Boy se acaba.

Todas estas observaciones han sido una tentativa más o menos estructuralista de entender el desarrollo del personaje principal. Pero le entendemos a Mudito mucho mejor si empleamos también un enfoque mitológico. Los psicólogos Carl G. Jung o Paul Radin, pór ejemplo, no habrán tenido ninguna dificultad en reconocer en Mudito el clásico "Tramposo", o "Trickster" estudiado a fondo por Radin en los mitos de los indios americanos. ${ }^{7}$ Igual a este personaje mítico, Mudito tiene la capacidad de cambiar de forma (lo vemos como una vieja, un adolescente, un perro). También igual al "Tramposo",

5 Op. cit., p. 500.

6 Op. cit., pp. 521-522.

7 Paul Radin, The Hero Cycles of the Winnebago (N. Y., 1948). 
tiene un pene enorme que también le gasta bromas. Cuando en su forma del gigante de cartón, Mudito pierde su enorme cabeza, todo lo que le queda es la nariz monstruosa, símbolo de su pene: "...a eso estoy reducido, mi enorme nariz transformada en falo, soy un falo lacio..." 8 Como el "Tramposo" o el bufón en la corte de Don Jerónimo, Mudito tiene privilegios que no serian otorgados a una persona normal: es testigo indispensable de la vida amorosa de su amo. Como persona medio loca, puede pertenecer al asilo de viejas chifladas y, como persona sin cara, al círculo de monstruos. Como "Tramposo", él manipula los dos mundos del subconsciente en sus relaciones con el mundo normal, exterior. Su libertad para salir de la Rinconada de los monstruos y su posesión de las llaves del asilo simbolizan su poder fálico de penetrar. ${ }^{9}$

Una figura del inconsciente, por fin Mudito se arregla para invadir y destruir la parte consciente de su ser que le ha negado existencia. $Y$ al destruir la "persona" de Don Jerónimo, al arrancarle la máscara de la belleza y sustituirle la máscara de la monstruosidad, Mudito el "Tramposo"' efectúa su propia muerte ya que el consciente y el inconsciente necesariamente comparten el mismo cuerpo.

Esta figura del "Tramposo" la relaciona Jung con las fiestas de la iglesia medieval donde la gente disfrazada de viejas, animales, monstruos, bailaban y jugaban en lugares sagrados y cantaban canciones indecentes. ${ }^{10} \mathrm{Y}$ esta fiesta del Rey Momo, hoy día conservado en la celebración del carnaval, tiene su paralelo en El obsceno pájaro de la noche. Por ejemplo, la huérfana, virgen según las viejas, baila indecentemente desde el púlpito del asilo: Donoso la retrata "bailando como una Virgen que se hubiera vuelto loca en su horacina." " novelístico de Donoso donde hay bailes constantes organizados por los monstruos y donde hay monstruosos santos construidos por las viejas, utilizando estatuas viejas que ellas convierten en "imbunches".

Seria demasiado largo señalar todos los episodios en los cuales Mudito demuestra la naturaleza doble del "Tramposo" que Jung caracteriza como la personificación de rasgos de carácter que a veces son mejores y a veces peores que aquellos poseídos por la personalidad del "ego". ${ }^{12}$ Quizá bastará mencionar que maliciosamente engaña a la huérfana y a Inés como brujo malo, y como Cristo, asume las heridas destinadas a su amo. De todas maneras queda claro que Donoso ha fundido su propio mito del "imbunche" con la vieja figura arquetípica del "Tramposo" para crear el personaje de Mudito.

De manera semejante, el "chonchón" del relato, "la cabeza terrible que en' las noches volaba por el aire" y seguía "una perra amarilla, verrugosa y flaca como su nana", 13 es otra adaptación de la vieja figura arquetípica que Jung ha nombrado el "Anima". Esta figura, según Jung, es el arquetipo de la vida misma, ambivalente,

8 Op. cit., p. 114.

9 Erich Neumann, The Great Mother (Princeton University Press, 1963), p. 170.

${ }^{10}$ C.G. Jung, Four Archetypes (Bollingen, paperback edition, 1970), pp. 136-140, (Jung señala también que la comedia del Renacimiento con sus inevitables Polichinelas es otra manifestación del poder y de la durabilidad de esta figura arquetípica, el "Tramposo"').

11 Op. cit., p. 20.

12 Jung, op. cit., p. 142 .

13. Op. cit., p. 36. 
doncella y madre, hada buena y bruja mala, inmortal o existente fuera del tiempo. ${ }^{14} \mathrm{Y}$ es solamente cuando desaparece la sombra de la otra figura de la subconciencia (que puede llamarse el Doble o el "Tramposo") que vemos esta figura numinosa que está escondida en sus tinieblas. ${ }^{15}$

Ahora bien, ya que hemos dispuesto de la sombra de Mudito, ha llegado el momento de enfocar la figura femenina de la novela, el personaje igualmente mágico de Inés-Peta Ponce. No hay duda que Inés es la reencarnación de la otra Inés, bruja del siglo XVIII. Tampoco hay duda que es también el chonchón y también la perra amarilla que corre a través de los siglos. Exactamente como Mudito fue el lado subconsciente de Jerónimo, Peta Ponce, por corresponder a la subconciencia, es el lado siniestro de Inés, su parte mágica que puede convertirse en chonchón o perra amarilla. Semejante a Mudito, ella también es necesaria a la vida de Inés. Como él, la Peta Ponce sufre el dolor de su ama:

La pobre Peta Ponce comenzó a enfermarse con los mismos dolores que yo había sentido, la Peta ha seguido sintiendo esos dolores míos toda la vida. ${ }^{16}$

Existe casi la misma dialéctica entre Inés (joven) y Peta Ponce que existía entre Mudito y Jerónimo, el mismo acercamiento hasta que al final las dos figuras se funden en la muerte. Y sin embargo, hay una diferencia importante. Aunque se supone que todos los personajes se mueren, en las últimas páginas de la novela todavia hay una perra y una vieja buscando comida, tratando de alimentarse con basura. De tal manera, el arquetipo de la vida ("Anima") sigue aún después de la desaparición de todos los personajes. En términos modernos se puede decir que esta figura es el arquetipo de la ecología que se aprovecha de todo (tal como las viejas del asilo tienen guardados como tesoros los trapos y desgastes de la sociedad). En la dialéctica a la cual nos hemos referido en el título, la figura del "Anima" se encarna en el chacal (otra manera de llamar a la perra amarilla). Y el "imbunche" (en su papel de "Tramposo" que ha jugado con la vida) tiene que ser sacrificado ante ella. El papel del "Anima" como comedora de carroña se puede entender mejor al referirnos a otras mitologías.

Entre los Aztecas este arquetipo se llamaba Coatlicue, la madre terrible, siempre representada con adornos de calaveras. En la mitología griega corresponde a la diosa Hécate, madre de tres caras, madre de brujería, diosa de las parturientas, de la locura(que se entendía como enfermedad de la luna) y cazadora salvaje acechando en la noche. La representaban casi siempre con perros y también recibía sacrificios de perros. Entre los egipcios se llama Isis, diosa que recogía los pedazos del cuerpo de Osiris con la ayuda del chacal, Anubis. En este mito los perros y los chacales, los dos comedores nocturnos de carroña, ayudan en la reconstrucción del dios. De tal manera se ve que el perro, o chacal, es también madre en el sentido de que su actuación es un recoger, parecido a la función del útero. (En la mitología egipcia los zopilotes también pueden simbolizar la madre y por las

14 Jung trata de este arquetipo a través de toda su obra. Veanse por ejemplo: "The Dual Mother", Symbols of Transformation (1911-12/1952); "Concerning the Archetypes, with Special Reference to the Anima Concept" (1936/1954), The Archetypes of the Collective Unconscious (todos del Bollingen Series XX, Princeton University Press).

15. Jung, Four Archetypes, pp. 150-151.

16 Op. cit., p. 185. 
mismas razones.) ${ }^{17}$

Quizá tiene mayor interés señalar el origen mítico de la perra amarilla en esta novela porque el mismo símbolo aparece también en una novela escrita anteriormente por Donoso, El lugar sin limites. En las dos obras se repite el tema de un señor feudal que sacrifica una perra amarilla a sus propios perros de caza como en un rito de fertilidad (acontecimiento que sugiere todos los elementos de la adoración de Hécate). De hecho, este tema, tanto como el de un protagnoista andrógino victimizado por un señor feudal, son comunes a las dos novelas. Solamente en la obra más reciente las tensiones y las dialécticas se enriquecen en forma casi barroca. Primero, como hemos visto en detalle, hay la dialéctica entre los lados consciente y subconsciente del personaje masculino, que es también la dialéctica interna entre la vida y la muerte. Con la victoria de la subconciencia (Mudito), partidario de la muerte, la primera dialéctica se acaba. (Podemos mencionar que demuestra el famoso deseo de la muerte señalado por Freud.) Pero una vez liberado de la existencia individual a través de la muerte, la subconciencia resiste su incorporación en otra forma. Quiere permanecer en la paz de no existir.

Es aquí donde empieza la actuación del chacal. La dialéctica sugerida en el título de este artículo, la última, es la dialéctica entre la subconciencia libre y el chacal (símbolo del "Anima") que trata de convertir a esta subconciencia en "imbunche" para después incorporarla en otra forma. $\mathrm{Y}$ el terror de la subconciencia, como vemos a través de la novela, es quedarse encarcelada como "imbunche" de las viejas. La tensión entre bruja e imbunche es la tensión entre Ser y No Ser. Pero el Ser no es el Ser existencial del hombre. Es un Ser telúrico. Equivale al No Ser, aquel gran miedo al cual se había referido Donoso.

A través de la novela el cuerpo de Mudito ha servido a los chacales humanos para crear con él nuevas formas de vida. Aunque él destruye su lado consciente, a su cuerpo no le es permitido descansar; tiene que entrar en otros cuerpos. A pesar de su voluntad, tiene un poder creativo de regenerar sus órganos sacados por el cirujano zopilotesco, el Dr. Azula, (a manera de otras criaturas primitivas). Por eso lo aprovechan todos los chacales hasta el final. Solamente allí, cuando su saco de "imbunche" queda completamente vacío, puede Mudito realizar su anhelo de paz. Pero el nirvana de Mudito es la pesadilla de Donoso. Es una victoria literalmente hueca. $Y$ esta victoria, según el autor, es la única posible frente al obsceno pájaro de la noche,-chonchón, zopilote, chacal, perra, bruja, Naturaleza. 
